\title{
Extraction and Bioactivity Analysis of Major Flavones Compounds from Scutellaria baicalensis Using In Vitro Assay and Online Screening HPLC-ABTS System
}

\author{
Kwang Jin Lee, Pil Mun Jung, You-Chang Oh, Na-Young Song, \\ Taesoo Kim, and Jin Yeul Ma
}

KM-Based Herbal Drug Development Group, Korean Institute of Oriental Medicine (KIOM), 1672 Yuseongdae-ro, Yuseong-gu, Daejeon 305-811, Republic of Korea

Correspondence should be addressed to Jin Yeul Ma; jyma@kiom.re.kr

Received 1 July 2014; Revised 18 August 2014; Accepted 18 August 2014; Published 1 September 2014

Academic Editor: Hassan Y. Aboul Enein

Copyright (C) 2014 Kwang Jin Lee et al. This is an open access article distributed under the Creative Commons Attribution License, which permits unrestricted use, distribution, and reproduction in any medium, provided the original work is properly cited.

The extraction efficiency of a number of solvent compositions for the improvement of bioactive compounds yield from S. baicalensis has been investigated. Also, free radical scavengers in the glycoside baicalin (BG), wogonoside (WG), aglycon baicalein (B), and wogonin (W) compounds of S. baicalensis were screened, identified, and quantified using coupled offline ABTS and online screening HPLC-ABTS assay. Increasing ethanol content fractions resulted in decreased extract yield of bioactive compounds. In this case, the best yield of $37.01 \mathrm{mg} / \mathrm{g}$ in BG, WG, B, and W compounds was obtained by a dipping method with an extraction time of $4 \mathrm{~h}$. In addition, the yield $(43.05 \%)$ and $\mathrm{IC}_{50}(34.04 \mu \mathrm{g} / \mathrm{mL})$ determined through $\mathrm{ABTS}$ assay of the $60 \%$ aqueous ethanol extract were the most satisfactory of all solvent solutions tested. This result shows that an online screening HPLC-ABTS assay can be a powerful technique for the rapid characterization of bioactivity compounds in plant extracts. Moreover, their anti-inflammatory activities were evaluated via analyzed inhibitory effect on NO and inflammatory cytokine production. Furthermore, WG and W exhibited the strong inhibitory effects on inflammatory mediator production including NO, IL-6, and IL-1 $\beta$ in LPS-stimulated RAW 264.7 macrophages.

\section{Introduction}

Scutellaria baicalensis is one of the most widely used medicinal herbs for the treatment of various inflammatory diseases, such as hepatitis, tumors, and diarrhea in East Asian countries $[1,2]$. S. baicalensis contains a variety of flavones, phenylethanoids, amino acids, sterols, and essential oils [3]. Its dried roots contain flavonoids such as baicalin, baicalein, wogonin, wogonin 7 -O-glucuronide, oroxylin A, and oroxylin A 7-O-glucuronide [4]. These four major flavones: glycoside baicalin (BG, MW; 446.37, $\mathrm{C}_{21} \mathrm{H}_{18} \mathrm{O}_{11}$ ), wogonoside (WG, MW; 460.39, $\mathrm{C}_{22} \mathrm{H}_{20} \mathrm{O}_{11}$ ), aglycon baicalein (B, MW; 270.24, $\mathrm{C}_{15} \mathrm{H}_{10} \mathrm{O}_{5}$ ), and wogonin (W, MW; 284.27, $\mathrm{C}_{16} \mathrm{H}_{12} \mathrm{O}_{5}$ ) were reported to be the main bioactive components in S. baicalensis $[5,6]$. Besides its anti-inflammation and anticancer properties, S. baicalensis is effective in treating bacterial and viral infections, reducing the total cholesterol level and decreasing blood pressure $[7,8]$. The bioactivities of BG and B are much more than those of WG and W [6]. In previous studies of extraction methods, a variety of approaches have been developed for the extraction of useful components from S. baicalensis, for instance, soxhlet extraction (SE), heating reflux extraction (HRE), supercritical fluid extraction (SFE) [9], ultrasonic assisted extraction (UAE) [10], and microwave assisted extraction (MAE) [11]. Moreover, water, methanol, ethanol, and ethyl acetate are commonly used solvents for the extraction of bioactive compounds from plant materials and oriental medicine herbs (OMHs). Identification of the bioactivity compounds in S. baicalensis has been achieved through several methods, including thin-layer chromatography (TLC), high performance liquid chromatography (HPLC), high-speed countercurrent chromatography (HSCCC), capillary electrophoresis 
(CE), and micellar electrokinetic capillary chromatography (MEKC) [12]. In the past few years, online screening with a HPLC postcolumn assay involving the DPPH or ABTS radical technique has been developed, allowing bioactive compounds to be spectrophotometrically monitored. Also, this method was successfully applied for screening and identifying natural bioactive compounds from complex mixtures, especially for extracts of OMHs $[13,14]$.

This work investigates applications of offline ABTS IC $_{50}$ assays and online screening HPLC-ABTS assays for bioactivity screening, so that a more practical approach may be taken towards the use of online screening HPLC-ABTS assays for the rapid pinpointing of bioactivity peaks in chromatograms finds expression in experimental. Additionally, various solvent extraction techniques are compared in terms of their yields of the four major compounds: glycoside baicalin (BG), wogonoside (WG), aglycon baicalein (B), and wogonin (W) compounds in S. baicalensis. And, their anti-inflammatory activities were evaluated via analyzed inhibitory effect on NO and inflammatory cytokine production.

\section{Experimental}

2.1. Reagents and Materials. The following reagents were used for radical-scavenging assays: ABTS (2,2' -azino-bis-3ethylbenzothiazoline-6-sulfonic acid), potassium persulfate, and trifluoroacetic acid (TFA) were purchased from Sigma. Co. (USA). The standard chemicals of baicalin (BG), wogonoside (WG), baicalein (B), and wogonin (W) were obtained from Sigma. Co. (USA). The dried root of S. baicalensis was purchased from the Yeongcheon market (Gyeongsangbukdo, South Korea) in March 2012. HPLC-grade ethanol, methanol, and acetonitrile were purchased from J. T. Baker (USA). The triple distilled water was filtered by a pump (Division of Millipore, Merck, Billerica, MA, USA) and filter (FH-0.2 $\mu \mathrm{m}$, Waters, Milford, MA, USA). Materials for cell culture were obtained from Lonza (Basel, Switzerland). LPS, Bovine serum albumin (BSA), and 3-(4,5-dimethylthiazol-2yl)-2,5-diphenylthiazolium bromide (MTT) were purchased from Sigma (St. Louis, MO, USA). Antibodies for ELISA were obtained from eBioscience (San Diego, CA, USA). The chemical structures of four major flavonoids $B G, B, W G$, and $\mathrm{W}$ are shown in Figure 1.

2.2. Standard Sample Preparation. The high purity standard sample (higher than $>95 \%$ ) was prepared by dissolving $2 \mathrm{mg}$ of the standard chemicals baicalin (BG), wogonoside (WG), baicalein (B), and wogonin (W) in $10 \mathrm{~mL}$ of methanol and adjusting the concentration to $200 \mathrm{ppm}$.

2.3. ABTS Sample Preparation. A $2 \mathrm{mM}$ ABTS stock solution containing $3.5 \mathrm{mM}$ potassium persulfate was prepared and was kept in the dark at room temperature for $16 \mathrm{~h}$ to allow the completion of radical generation and was then diluted with water $(1: 29, \mathrm{v} / \mathrm{v})$.

2.4. Solvent Extraction. $5 \mathrm{~g}$ samples of the dry powder from the $S$. baicalensis containing the four major flavonoids, BG,
WG, B, and $\mathrm{W}$, were loaded in $100 \mathrm{~mL}$ of pure $100 \%$ water, $100 \%$ ethanol, and $80 \%, 70 \%$, and $60 \%$ aqueous ethanol solution $100 \mathrm{~mL}$ by dipping method for $4 \mathrm{~h}$ at $25^{\circ} \mathrm{C}$. Each extract was filtered, concentrated under vacuum using rotaevaporator, and refrigerated for $48 \mathrm{~h}$. Then the samples were frozen dry and the total extraction yield was calculated. Each sample was filtered through a $0.2 \mu \mathrm{m}$ membrane filter prior to offline ABTS assay and online screening HPLC-ABTS analysis.

2.5. Extraction Yield. Each experiment was performed in two replicates and the data were subjected to calculations of means \pm SD. The extract sample was expressed as a percentage of the weight. The extraction yield was measured using (1). Also, samples were prepared by dissolving $100 \mathrm{mg}$ of the extracted solution in $2 \mathrm{~mL}$ of methanol and adjusting the concentration to $50 \mathrm{mg} / \mathrm{mL}$. The solutions were applied by ultracentrifuge for $10 \mathrm{~min}$ at $10,000 \mathrm{rpm}$. These solutions were filtered through a $0.2 \mu \mathrm{m}$ membrane filter prior to analysis. Consider the following:

$$
\text { Extraction yield }(\%)=\frac{\text { Extracts dry weight }}{\text { Sample dry weight }} \times 100 \text {. }
$$

2.6. Offline ABTS Assay for Bioactivity Evaluation. The ABTS radical cation method [15] was modified to evaluate the free radical-scavenging effect of $S$. baicalensis extracts. The ABTS reagent was prepared by mixing $5 \mathrm{~mL}$ of $7 \mathrm{mM}$ ABTS with $88 \mu \mathrm{L}$ of $140 \mathrm{mM}$ potassium persulfate. The mixture was then kept in the dark at room temperature for $16 \mathrm{~h}$ to allow free radical generation and was then diluted with water $(1: 44, \mathrm{v} / \mathrm{v})$. To determine the scavenging activity, $100 \mu \mathrm{L}$ ABTS reagent was mixed with $100 \mu \mathrm{L}$ of sample in a 96-well microplate and was incubated room temperature for $6 \mathrm{~min}$. After incubation, the absorbance was measured $734 \mathrm{~nm}$ using an ELISA reader (TECAN, Gröding, Austria), and 100\% methanol was used as a control. The ABTS scavenging effect was measured using the following formula:

$$
\text { Radical scavenging }(\%)=\frac{(A) \text { control }-(A) \text { sample }}{(A) \text { control }} \times 100 \text {. }
$$

The $\mathrm{IC}_{50}$ ABTS values (the concentration of sample required to inhibition $50 \%$ of ABTS radicals) were obtained through extrapolation from regression analysis. The bioactivity was evaluated based on this $\mathrm{IC}_{50}$ value.

2.7. Online Screening HPLC-ABTS Assay Analysis. The online radical-scavenging activity of $S$. baicalensis was determined using the ABTS assay modified the methods used by Stewart et al. [16]. A $2 \mathrm{mM}$ ABTS stock solution containing $3.5 \mathrm{mM}$ potassium persulphate was prepared and was kept in the dark at room temperature for $16 \mathrm{~h}$ to allow the completion of radical generation and was then diluted with water $(1: 29$, $\mathrm{v} / \mathrm{v})$. S. baicalensis extract was injected into a Dionex Ultimate 3000 HPLC system (Thermo scientific). The chromatographic columns used in this experiment are commercially available; this is obtained from RS-tech $(0.46 \times 25 \mathrm{~cm}, 5 \mu \mathrm{m}$, 
<smiles>[R3]c1c([R])c([R])c2c(=O)cc(-c3ccccc3)oc2c1[R1]</smiles>

Flavones

\begin{tabular}{cllccc}
\hline & Compounds & R1 & R2 & R3 & R4 \\
\hline \multirow{2}{*}{ Glycoside } & Baicalin (BG) & OH & OH & O-Glucuronic acid & $\mathrm{H}$ \\
& Wogonoside (WG) & OH & H & O-Glucuronic acid & OMe \\
& Baicalein (B) & OH & OH & OH & $\mathrm{H}$ \\
& Wolycon & OH & H & OH & OMe \\
\hline
\end{tabular}

FIGURE 1: Chemical structure of baicalin, wogonoside, baicalein, and wogonin compounds in S. baicalensis.

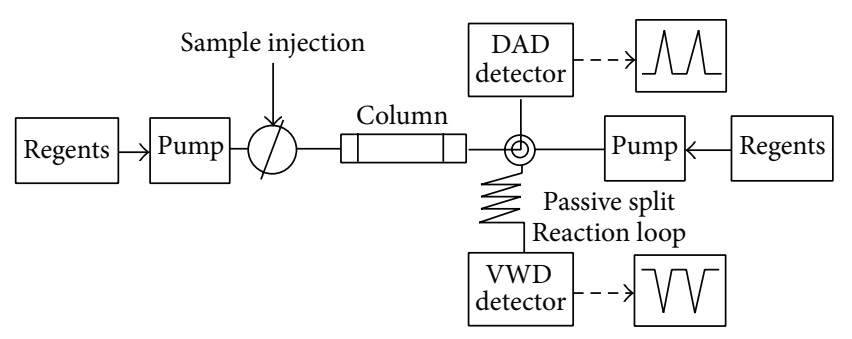

FIGURE 2: Schematic of online screening HPLC-ABTS system.

$\mathrm{C}_{18}$, Daejeon, Korea). The injection volume was $10 \mu \mathrm{L}$, and the flow rate of the mobile phase was $1.0 \mathrm{~mL} / \mathrm{min}$. The wavelength of the UV detector was fixed at $275 \mathrm{~nm}$. The compositions of the mobile phases were A, water/trifluoroacetic acid = $99.9 / 0.1$, vol\% and B, acetonitrile $100 \%$. The run time was $80 \mathrm{~min}$ and the solvent program was the linear gradient method (90:10-60:40, A : B vol\%). Figure 2 is a schematic showing the online coupling of HPLC to a DAD (Diode Array Detector) and the continuous flow ABTS assay. Online HPLC then arrived at a " $T$ " piece, where ABTS was added. The ABTS flow rate was $0.5 \mathrm{~mL} / \mathrm{min}$, delivered by a Dionex Ultimate 3000 Pump. After mixing through a $1 \mathrm{~mL}$ loop which was maintained at $40^{\circ} \mathrm{C}$, the absorbance was measured by a VIS detector at $734 \mathrm{~nm}$. Data were analyzed using Chromeleon 7 software.

2.8. Cell Culture and Drug Treatment. RAW 264.7 cells were obtained from Korea Cell Line Bank (Seoul, Korea) and grown in RPMI 1640 medium containing 10\% FBS and $100 \mathrm{U} / \mathrm{mL}$ of antibiotics sulfate. The cells were incubated in humidified $5 \% \mathrm{CO}_{2}$ atmosphere at $37^{\circ} \mathrm{C}$. To stimulate the cells, the medium was changed with fresh RPMI 1640 medium and LPS $(200 \mathrm{ng} / \mathrm{mL})[17,18]$ was added in the presence or absence of four compounds $(1,3,5$, and $10 \mu \mathrm{M})$ for $24 \mathrm{~h}$.

2.9. Cell Viability Assay. Cytotoxicity was analyzed using a cell counting kit (CCK, Dojindo, Japan). Four compounds were added to the cells and incubated for $24 \mathrm{~h}$ at $37^{\circ} \mathrm{C}$ with $5 \% \mathrm{CO}_{2}$. CCK solutions were added to each well and the cells were incubated for another $1 \mathrm{~h}$. Then the optical density was read at $450 \mathrm{~nm}$ using an ELISA reader (Infinite M200, Tecan, Männedorf, Switzerland).

2.10. Measurement of NO Production. NO production was analyzed by measuring the nitrite in the supernatants of cultured macrophage cells. The cells were pretreated with five compounds and stimulated with LPS for $24 \mathrm{~h}$. The supernatant was mixed with a same volume of Griess reagent (1\% sulfanilamide, $0.1 \%$ naphthylethylenediamine dihydrochloride, and $2.5 \%$ phosphoric acid) and incubated at room temperature (RT) for $5 \mathrm{~min}$ [17]. The absorbance at $570 \mathrm{~nm}$ was read.

2.11. Determination of TNF- $\alpha, I L-6$, and $I L-1 \beta$ Cytokine Production. Cells were seeded at a density of $5 \times 10^{5}$ cells/mL in 24-well culture plates and pretreated with various concentrations of four compounds for $30 \mathrm{~min}$ before LPS stimulation. ELISA plates (Nunc, Roskilde, Denmark) were coated overnight at $4^{\circ} \mathrm{C}$ with capture antibody diluted in coating buffer ( $0.1 \mathrm{M}$ carbonate, $\mathrm{pH} 9.5)$ and then washed five times with phosphate-buffered saline (PBS) containing $0.05 \%$ Tween 20. The nonspecific protein-binding sites were blocked with assay diluent buffer (PBS containing 10\% FBS, pH 7.0) for more than 1 hour. Promptly, samples and standards were added to the wells. After 2 hours of incubation at RT or overnight at $4^{\circ} \mathrm{C}$, the working detector solution (biotinylated detection antibody and streptavidin-HRP reagent) was added and incubated for 1 hour. Subsequently, substrate solution (tetramethylbenzidine) was added to the wells and incubated for $30 \mathrm{~min}$ in darkness before the reaction was stopped with stop solution $\left(\mathrm{NH}_{3} \mathrm{PO}_{4}\right)$. The optical density was read at $450 \mathrm{~nm}$ [17].

2.12. Statistical Analysis. The results are expressed as mean $\pm \mathrm{SD}$ values for the number of experiments. Statistical significance was compared each treated group with the control 
TABLE 1: Yield of extraction solvent composition and bioactivity of the $S$. baicalensis extracts by free radical-scavenging activity ABTS $\mathrm{IC}_{50}$ assay.

\begin{tabular}{lcc}
\hline Extraction solvent & Extraction yield $(\%)$ & $\mathrm{IC}_{50}(\mu \mathrm{g} / \mathrm{mL})$ \\
\hline Water $100 \%$ & $18.36 \pm 0.25^{\mathrm{a}}$ & $302.17 \pm 37.40^{\mathrm{b}}$ \\
EtOH $100 \%$ & $1.97 \pm 0.01$ & $80.69 \pm 2.10$ \\
EtOH $80 \%$ & $23.00 \pm 0.90$ & $44.87 \pm 4.76$ \\
EtOH 70\% & $33.10 \pm 0.10$ & $39.22 \pm 2.74$ \\
EtOH 60\% & $43.05 \pm 0.47$ & $34.04 \pm 3.22$ \\
\hline
\end{tabular}

${ }^{\mathrm{a}}$ Each value in mean $\pm \mathrm{SD}(n=2) ;{ }^{\mathrm{b}}$ each value in mean $\pm \mathrm{SD}(n=3)$.

and determined by Student's $t$-tests. Each experiment was repeated at least three times to yield comparable results. Values with $P<0.01$ and $P<0.001$ were considered significant.

\section{Result and Discussion}

3.1. Extraction from S. baicalensis. Components from $\mathrm{OMHs}$ can be extracted using various extraction methods, and the extraction efficiency and component contents vary according to the extraction method. This study investigated the extraction efficiency, composition, and bioactivity of components from S. baicalensis using various solvent extractions. Different solvents used for the optimization of the extraction of major flavone compounds from $S$. baicalensis were water, ethanol, and $80 \%, 70 \%$, and $60 \%$ aqueous ethanol. Increasing ethanol percentage decreased the yield of extracted bioactive compounds. The extraction efficiencies obtained using $60 \%$, $70 \%$, and $80 \%$ aqueous ethanol are $43.05 \%, 33.10$, and $23 \%$, respectively. Moreover, the yield and bioactivity (radical scavenging) obtained using pure water and ethanol extractions were lower than those obtained using mixed aqueous ethanol solvents (Table 1).

3.1.1. Offline ABTS Assay. ABTS is one of the compounds that have a proton free radical, with a characteristic absorption, which decreases significantly upon exposure to proton radical scavengers. It is well accepted that the ABTS radical scavenging by bioactivity is attributable to their hydrogendonating ability. Accordingly, as shown in Figure 3, the ABTS radical-scavenging activity of $100 \%$ water, $100 \%$ ethanol, and $80 \%, 70 \%$, and $60 \%$ aqueous ethanol, extract from S. baicalensis was shown to occur in a dose-dependent manner. Of these, the $60 \%$ aqueous ethanol extract showed the strongest activity. Overall, the aqueous ethanol extracts showed better inhibitory activity against the ABTS radical than water extracts. The concentration required to inhibit $50 \%$ radical-scavenging effect $\left(\mathrm{IC}_{50}\right)$ was determined through testing a series of concentrations. The $\mathrm{IC}_{50}$ values of $100 \%$ water, $100 \%$ ethanol, and $80 \%, 70 \%$, and $60 \%$ aqueous ethanol extracts were $302.17,80.69,44.87,39.22$, and $39.22 \mu \mathrm{g} / \mathrm{mL}$, respectively. The study of Park et al. showed that the DPPH $\mathrm{IC}_{50}$ value of $S$. baicalensis crude extract was $290 \mu \mathrm{g} / \mathrm{mL}$, which is similar to the result from a water extract in this study [19]. The figure is higher than that of this study, but there is

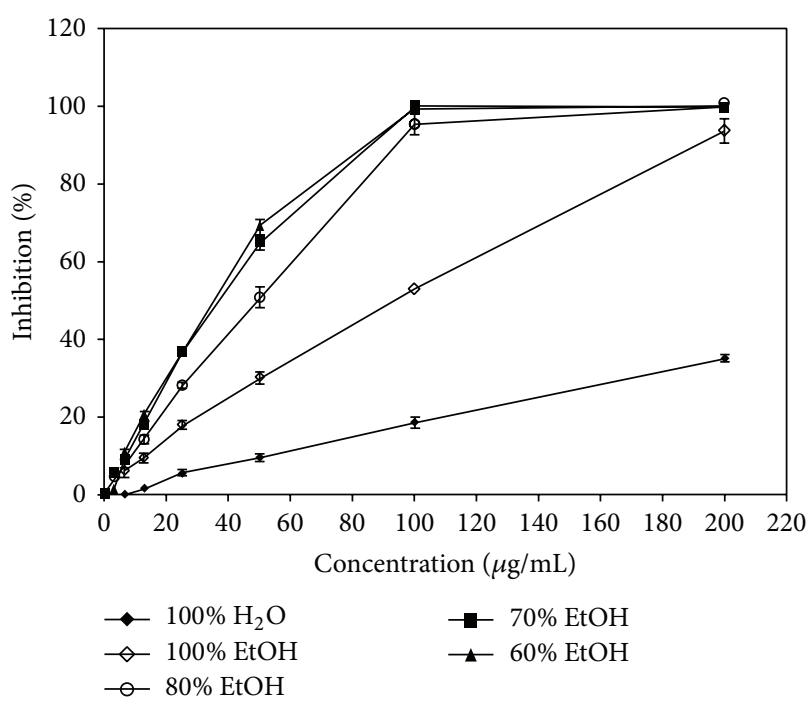

FIGURE 3: Free radical-scavenging activity of S. baicalensis extracts by ABTS assay. $(\diamond)$ Water, $(\diamond) 100 \% \mathrm{EtOH},(\bigcirc) 80 \% \mathrm{EtOH},(\boldsymbol{\nabla}) 70 \%$ $\mathrm{EtOH}$, and $(\boldsymbol{\Delta}) 60 \% \mathrm{EtOH}$, results are mean \pm S.D $(n=3)$.

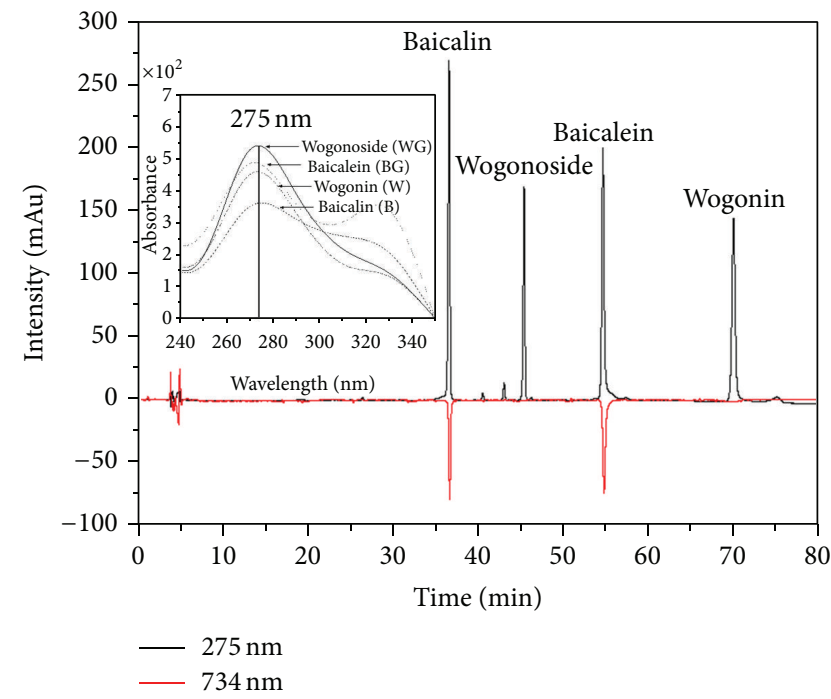

FIGURE 4: Chromatogram of online screening HPLC-ABTS radical scavenging of standard chemical compounds.

a significant difference between two experimental methods. Consequently, this study shows that $60 \%$ aqueous ethanol has the highest bioactivity, while the $100 \%$ water extract has the lowest value. Thus, it is considered that using a water-ethanol mixture extract is suitable for water-ethanol mixture extract is higher than that of water or ethanol extract.

3.1.2. Online HPLC-ABTS Assay Analysis. The HPLC separated analyses react after column with the ABTS and the reduction is detected as a negative peak by a VIS absorbance detector at $734 \mathrm{~nm}$. As the ABTS radical is much more water soluble than DPPH, the ABTS assay is more widely used for 


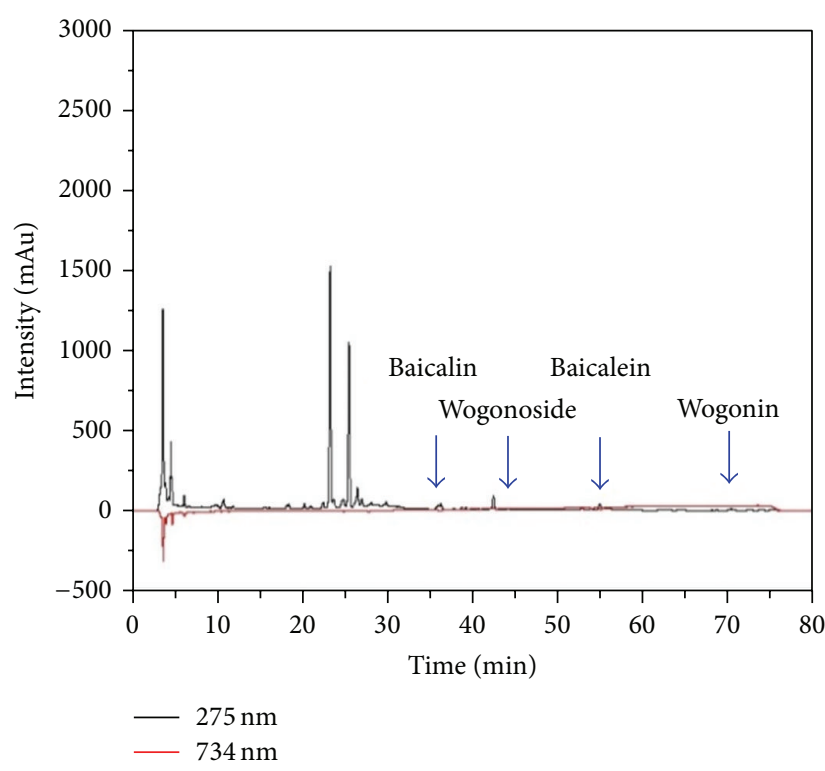

(a)

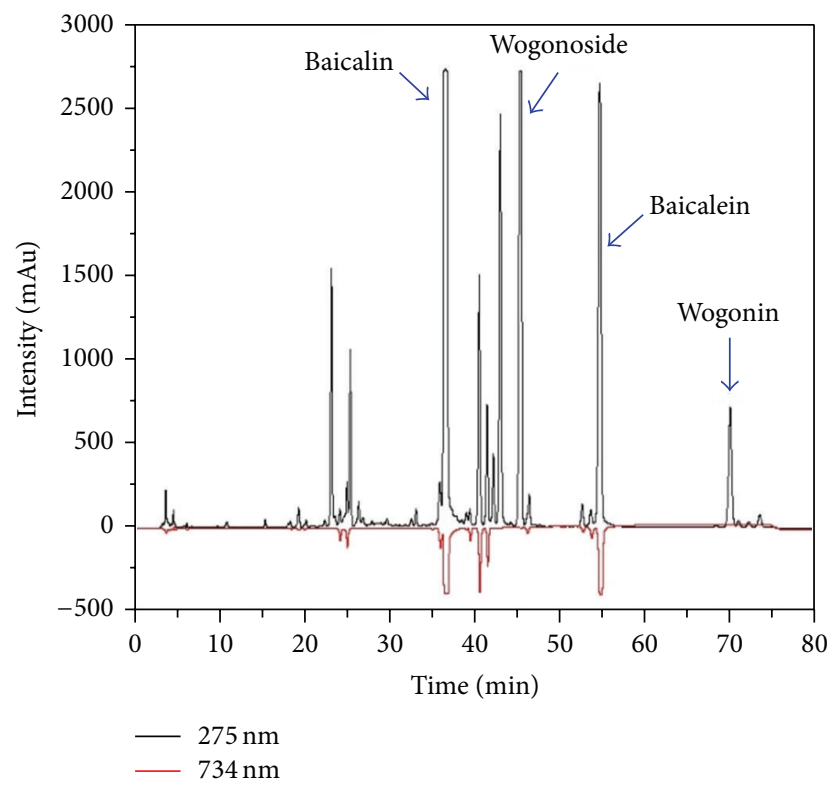

(c)

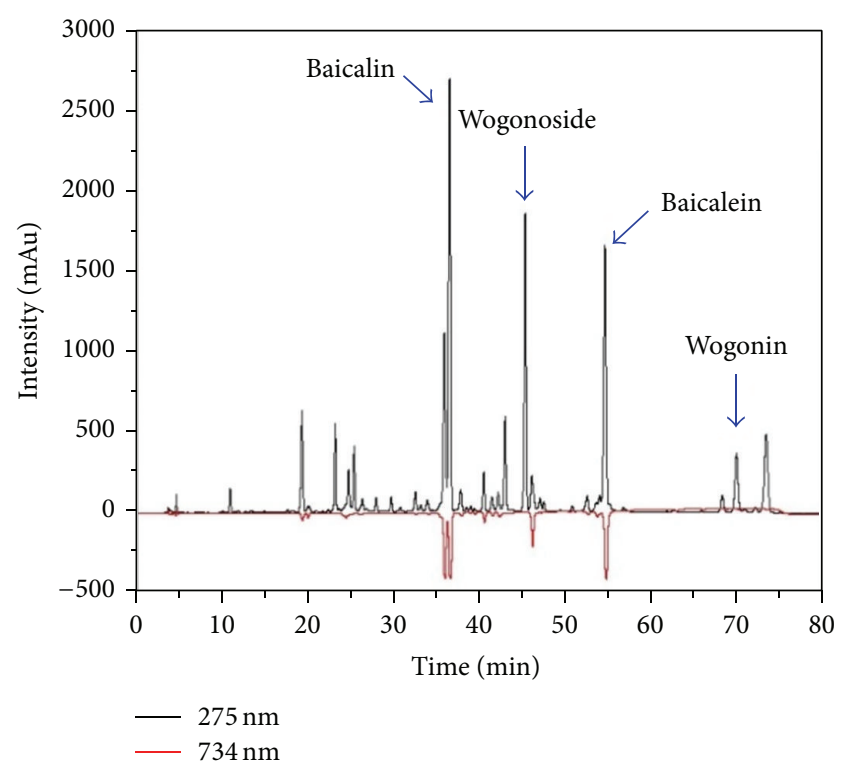

(b)

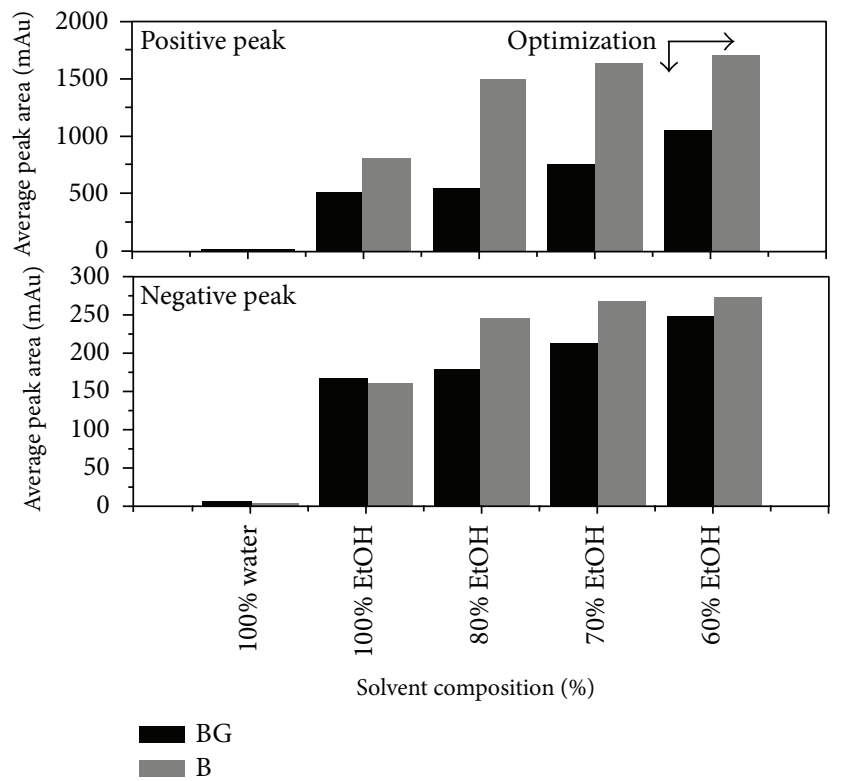

(d)

FIGURE 5: Chromatogram and column symbol of online screening HPLC profile of S. baicalensis extracts. Upper profile: UV signal at $275 \mathrm{~nm}$, lower profile: ABTS reduction signal at $734 \mathrm{~nm}$, (a) $100 \%$ water, (b) $100 \% \mathrm{EtOH}$, (c) $60 \% \mathrm{EtOH}$, and (d) negative and positive average peak area.

evaluation of water bioactivities. Combined UV (positive signals) and ABTS quenching (negative signals) chromatograms of the different $S$. baicalensis extracts and standard chemical $(200 \mathrm{ppm})$ are presented in Figures 4 and 5. Several eluted flavonoids in the extract were detected, including BG, WG, B, and $\mathrm{W}$ giving a positive signal on the UV detector $(275 \mathrm{~nm})$. Among them, the others showed hydrogen-donating capacity (negative peak) towards the ABTS radical at the applied concentration. These results revealed that the method can be applied for a quick screening of bioactivity, or more precisely, of radical-scavenging activity of compounds. In this case, BG and B were determined chromatographically, confirming their bioactivity though WG or W was not detected. This means that BG and B have the high bioactivity, whereas WG and $\mathrm{W}$ have the low bioactivity. In addition, Gao et al. [6] elicited similar results using a DPPH assay method. It shows 
TABLE 2: Comparison of extracts efficiency by online screening HPLC-ABTS in positive and negative peak area.

\begin{tabular}{|c|c|c|c|c|c|c|c|c|c|c|}
\hline \multirow[b]{2}{*}{$\begin{array}{l}\text { Extraction } \\
\text { solvent } \\
(\%)\end{array}$} & \multirow[b]{2}{*}{ Compounds } & \multirow[b]{2}{*}{$\begin{array}{c}R_{t} \\
(\min )\end{array}$} & \multicolumn{5}{|c|}{ Positive peak } & \multicolumn{3}{|c|}{ Negative peak } \\
\hline & & & $\begin{array}{c}\text { Average } \\
\text { peak area } \\
(\mathrm{mAU})\end{array}$ & $\begin{array}{c}\text { Standard } \\
\text { deviation } \\
(\mathrm{SD} \pm)\end{array}$ & $\begin{array}{c}\mathrm{RSD}^{\mathrm{a}} \\
(\%)\end{array}$ & $\begin{array}{l}\text { Yield } \\
(\%)\end{array}$ & $\begin{array}{c}\text { Total } \\
\text { extraction } \\
\text { amount } \\
(\mathrm{mg})\end{array}$ & $\begin{array}{c}\text { Average } \\
\text { peak area } \\
(\mathrm{mAU})\end{array}$ & $\begin{array}{c}\text { Standard } \\
\text { deviation } \\
(\mathrm{SD} \pm)\end{array}$ & $\begin{array}{l}\text { RSD } \\
(\%)\end{array}$ \\
\hline \multirow{4}{*}{$\begin{array}{l}100 \% \\
\text { Water }\end{array}$} & BG & 54.76 & 12.80 & 2.54 & 19.86 & 1.07 & 0.21 & 6.01 & 0.01 & 0.08 \\
\hline & WG & 45.53 & 0.20 & 0.22 & 114.26 & 0.01 & 0.01 & $\mathrm{ND}^{\mathrm{b}}$ & - & - \\
\hline & B & 36.42 & 8.71 & 10.32 & 118.52 & 0.96 & 0.13 & 2.76 & 3.91 & 141.42 \\
\hline & $\mathrm{W}$ & 70.11 & 2.93 & 1.32 & 45.18 & 0.23 & 0.04 & $\mathrm{ND}$ & - & - \\
\hline \multirow{4}{*}{$\begin{array}{l}100 \% \\
\text { Ethanol }\end{array}$} & BG & 54.77 & 505.72 & 26.58 & 5.26 & 12.84 & 0.90 & 166.45 & 1.79 & 1.08 \\
\hline & WG & 45.48 & 468.99 & 24.32 & 5.19 & 11.91 & 1.21 & ND & - & - \\
\hline & $\mathrm{B}$ & 36.18 & 803.00 & 126.99 & 15.81 & 20.15 & 1.32 & 161.15 & 15.61 & 9.69 \\
\hline & $\mathrm{W}$ & 70.18 & 164.19 & 13.56 & 8.26 & 4.16 & 0.24 & ND & - & - \\
\hline \multirow{4}{*}{$\begin{array}{l}80 \% \\
\text { Aqueous } \\
\text { ethanol }\end{array}$} & $\mathrm{BG}$ & 54.74 & 545.35 & 31.60 & 5.80 & 8.41 & 11.42 & 179.00 & 13.59 & 7.59 \\
\hline & WG & 45.47 & 1258.84 & 232.65 & 18.48 & 19.10 & 38.08 & ND & - & - \\
\hline & B & 36.60 & 1492.57 & 372.90 & 24.98 & 22.46 & 28.79 & 244.52 & 49.46 & 20.23 \\
\hline & $\mathrm{W}$ & 70.03 & 292.71 & 16.91 & 5.78 & 4.51 & 4.99 & ND & - & - \\
\hline \multirow{4}{*}{$\begin{array}{l}70 \% \\
\text { Aqueous } \\
\text { ethanol }\end{array}$} & BG & 54.76 & 753.16 & 26.72 & 3.55 & 11.34 & 22.70 & 211.85 & 21.91 & 10.34 \\
\hline & WG & 45.50 & 1249.30 & 208.61 & 16.70 & 18.53 & 54.40 & ND & - & - \\
\hline & B & 36.68 & 1634.98 & 384.09 & 23.49 & 24.07 & 45.40 & 267.07 & 53.40 & 20.00 \\
\hline & $\mathrm{W}$ & 70.06 & 300.91 & 16.19 & 5.38 & 4.52 & 7.39 & ND & - & - \\
\hline \multirow{4}{*}{$\begin{array}{l}60 \% \\
\text { Aqueous } \\
\text { ethanol }\end{array}$} & $\mathrm{BG}$ & 54.78 & 1049.88 & 34.23 & 3.26 & 15.12 & 41.46 & 246.00 & 29.69 & 12.07 \\
\hline & WG & 45.51 & 1246.60 & 104.08 & 8.35 & 17.78 & 71.14 & ND & - & - \\
\hline & B & 36.59 & 1710.77 & 194.19 & 11.35 & 24.26 & 62.26 & 272.92 & 56.03 & 20.53 \\
\hline & $\mathrm{W}$ & 70.05 & 314.99 & 6.94 & 2.20 & 4.55 & 10.13 & ND & - & - \\
\hline
\end{tabular}

${ }^{\mathrm{a}} \mathrm{RSD}$ : relative standard deviation; ${ }^{\mathrm{b}} \mathrm{ND}$ : not detected.

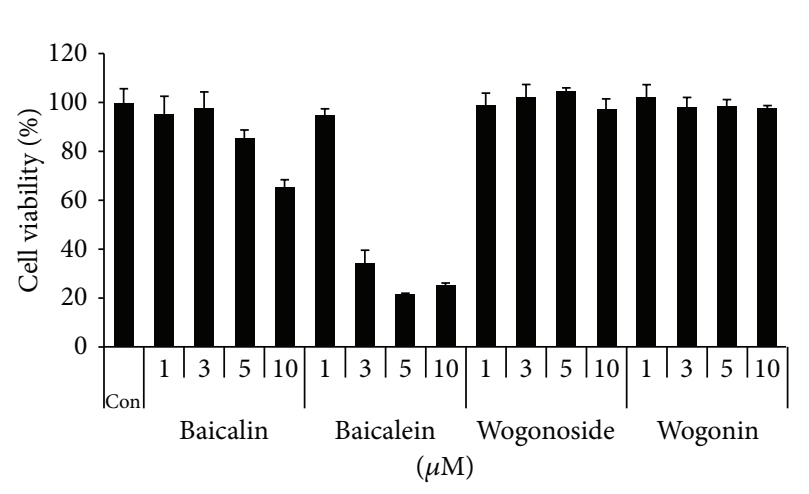

(a)

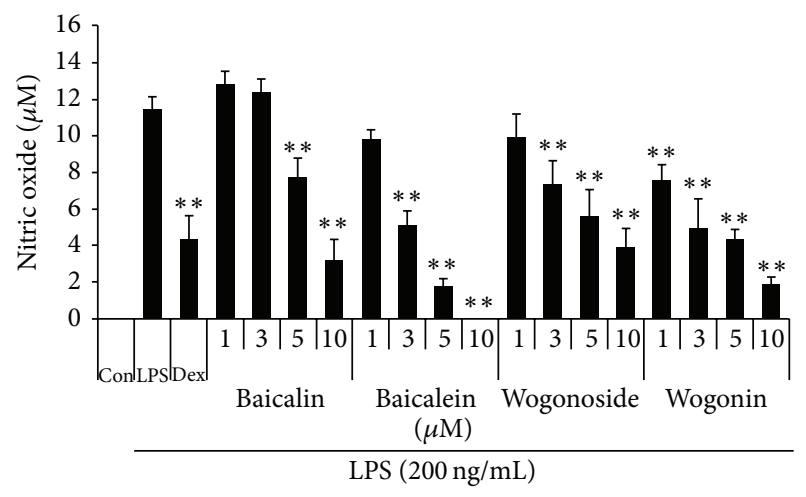

(b)

FIGURE 6: Effect of four compounds on (a) cell viability and LPS-induced (b) NO production in RAW 264.7 cells. RAW 264.7 cells were pretreated with four compounds for $30 \mathrm{~min}$ before incubation with LPS for $24 \mathrm{~h}$. (a) Cytotoxicity was evaluated by a CCK. (b) The culture supernatant was analyzed for nitrite production. As a control, the cells were incubated with vehicle alone. Data shows mean \pm SE values of triplicate determination from independent experiments. ${ }^{*} P<0.01$ and ${ }^{* *} P<0.001$ were calculated from comparing with LPS-stimulation value.

the details of an online HPLC-ABTS assay system which analyzes the extracts from solvents (Figures 5(a)-5(d)). The retention time $\left(R_{t}\right)$ of glycoside BG $\left(R_{t}: 54.74 \sim 54.87 \mathrm{~min}\right)$ and WG $\left(R_{t}: 45.47 \sim 45.53 \mathrm{~min}\right)$ and aglycone $\mathrm{B}\left(R_{t}: 36.18 \sim\right.$ $36.68 \mathrm{~min})$ and $\mathrm{W}\left(R_{t}: 70.03 \sim 70.18 \mathrm{~min}\right)$ was reported by this work. The $60 \%$ aqueous ethanol extract resulted in the greatest total extraction amount (BG: 41.46, WG: 71.14, B: 62.26, and $\mathrm{W}: 10.13 \mathrm{mg}$ ) were the total extraction amount highest them $70 \%$ aqueous ethanol extract (BG: 22.70, WG: 54.40, B: 45.40 , and $\mathrm{W}: 7.39 \mathrm{mg}), 80 \%$ aqueous ethanol extract (BG: 


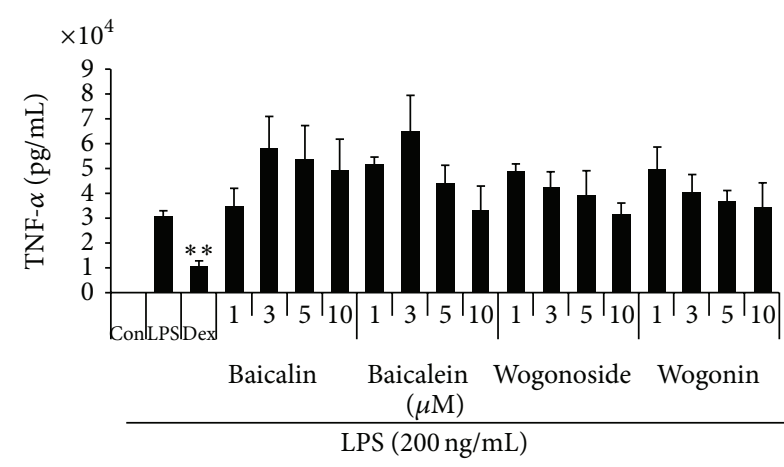

(a)

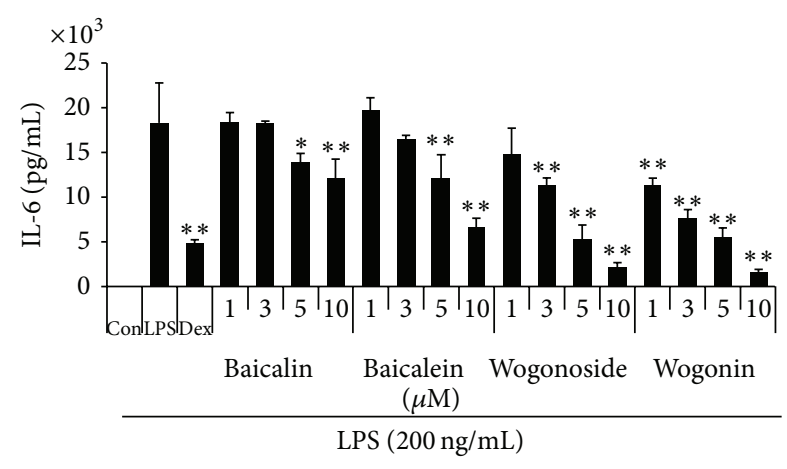

(b)

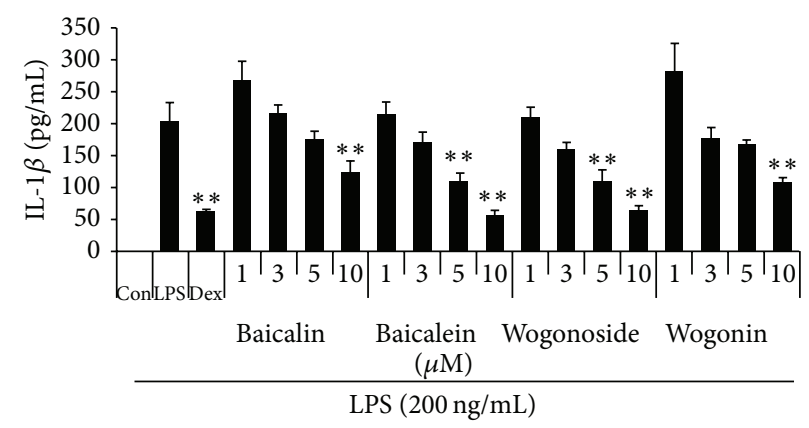

(c)

Figure 7: Effect of four compounds on the production of (a) TNF- $\alpha$, (b) IL-6, and (c) IL-1 $\beta$ cytokine in macrophages. Cells were pretreated with four compounds for 30 min before being incubated with LPS for $24 \mathrm{~h}$. Production of cytokines was measured by ELISA. Data shows mean \pm SE values of duplicate determinations from three independent experiments. ${ }^{*} P<0.01$ and ${ }^{* *} P<0.001$ were calculated from comparing with LPS-stimulation value.

11.42, WG: $38.08, \mathrm{~B}: 28.79$, and W: $4.99 \mathrm{mg}$ ), $100 \%$ ethanol extract (BG: 0.09, WG: 1.21, B: 1.32, and W: $0.24 \mathrm{mg}$ ), and 100\% water extract (BG: 0.21, WG: 0.01, B: 0.13, and W: $0.04 \mathrm{mg}$ ). Bioactivity of the $60 \%$ aqueous ethanol extract (BG: 246.00 , $\mathrm{B}: 272.92 \mathrm{mAU}$ ) was the highest of all, as compared to the $70 \%$ aqueous ethanol extract (BG: 211.85, B: $267.07 \mathrm{mAU}$ ), $80 \%$ aqueous ethanol extract (BG: 179.00, B: $244.52 \mathrm{mAU}$ ), $100 \%$ ethanol extract (BG: 166.45, B: $161.15 \mathrm{mAU}$ ), and 100\% water extract (BG: 6.01, B: $2.76 \mathrm{mAU}$ ). The bioactivity appears to be approximately proportional to the concentration of BG and $\mathrm{B}$ contained in the extracts. Bioactivity was not detected for WG and W, and therefore they should not exert any effect of bioactivity (radical-scavenging activity) (Table 2). Moreover, most research has focused on the transformation of BG and WG to improve the yield of B and W [20]. The major effective flavones BG and B were reported to be bioactive components [21]. Also, glycosides BG and WG were the most abundant components and have antiallergic, anti-inflammatory, antiHIV, antioxidant, and free radical-scavenging effects [22]. This work confirms the feasibility of assessing the bioactivity of specific phytochemicals, using an online screening HPLCABTS assay method. It was successfully applied for screening and identifying natural bioactivity from OMHs and natural substance complex mixtures.

\subsection{Anti-Inflammatory Activities Screening}

3.2.1. Effect of Four Compounds on RAW 264.7 Cell Viability. We evaluated the cytotoxicity of four compounds using a
CCK to determine the optimal concentration that would be effective for anti-inflammation with minimum toxicity. As shown in Figure 6(a), baicalin shows little toxicity at concentration of $10 \mu \mathrm{M}$. Also, baicalein contains strong toxicity on macrophage viability at $3 \mu \mathrm{M}$ or more. Wogonoside and wogonin did not affect cell viability up to $10 \mu \mathrm{M}$, indicating two compounds are not toxic to cells.

3.2.2. Effect of Four Compounds on NO Production in LPS-Stimulated RAW 264.7 Macrophages. We evaluated the effects of four compounds on NO secretion in LPS-stimulated RAW 264.7 cells. The cells were pretreated with four compounds at various concentrations prior to LPS stimulation and NO production was measured. As a positive control, we employed $10 \mu \mathrm{M}$ dexamethasone, which is widely employed as an anti-inflammatory agent. As shown in Figure 6(b), baicalin shows slightly inhibitory effect on NO secretion upon LPS stimulation at $5 \mu \mathrm{M}$. Baicalein repressed $\mathrm{NO}$ secretion at concentrations of $3 \mu \mathrm{M}$ or more. However, this inhibitory effect was related with strong cytotoxicity of baicalein [18]. Wogonoside and wogonin were strongly inhibited NO production in a dose-dependent manner with statistical significance.

\subsubsection{Effect of Four Compounds on LPS-Induced Inflammatory} Cytokines Production. Next, we investigated the inhibitory effect of four compounds on the production of inflammatory cytokines, which is another parameter of inflammation. In 
this study, we examined the effect of four compounds on TNF- $\alpha$, IL- 6 , and IL- $1 \beta$ cytokine production. As shown in Figure 7(a), all compounds did not inhibit TNF- $\alpha$ production at all concentrations. As shown in Figure 7(b), wogonoside and wogonin were significantly inhibited IL-6 cytokine secretion at concentrations of $3 \mu \mathrm{M}$ or more with statistical significance. Consistent with IL-6 results, wogonoside and wogonin showed inhibitory effect on IL-1 $\beta$ cytokine production in a dose-dependent fashion (Figure 7(c)).

\section{Conclusions}

This study provides the comparison of free radical scavengers in the extracts of $S$. baicalensis by an offline ABTS assay and an online screening HPLC-ABTS assay. The results showed the effect of solvent composition on total extraction yield from S. baicalensis. Based on our investigations, total extract yield and bioactivity decreased with ethanol increasing in the solvent mixture. In addition, the bioactivities of BG and B were determined to be much greater than those of WG or $\mathrm{W}$. The yield $(43.05 \%)$ and $\mathrm{IC}_{50}(34.04 \mu \mathrm{g} / \mathrm{mL})$ determined through ABTS assay of the $60 \%$ aqueous ethanol extract were the most satisfactory of all solvent solutions tested. And, this confirms the feasibility of assessing the bioactivity of specific phytochemicals using the online screening HPLC-ABTS assay. There was a very small margin of error between the results of the offline ABTS assay and those of the online screening HPLC-ABTS assay. Moreover, their anti-inflammatory activities were evaluated via analyzed inhibitory effect on NO and inflammatory cytokine production. Furthermore, WG and W exhibited the strong inhibitory effects on inflammatory mediator production including NO, IL-6, and IL-1 $\beta$ in LPS-stimulated RAW 264.7 macrophages. In conclusion, these compounds could be developed as a new anti-inflammatory therapeutic agent without cytotoxicity. These results will be compiled as a database, for use in investigating the constituents of natural products and the resources of pharmaceutical, nutrition, and cosmetic products.

\section{Conflict of Interests}

The authors declare that there is no conflict of interests regarding the publication of this paper.

\section{Acknowledgments}

This study was achieved at KM-Based Herbal Drug Development Group, KIOM. The authors also acknowledge the support from the "Study on drug efficacy enhancement using bioconversion for herbal medicines" (K14050) project.

\section{References}

[1] K. Ishimaru, K. Nishikawa, T. Omoto, I. Asai, K. Yoshihira, and K. Shimomura, "Two flavone 2 '-glucosides from Scutellaria baicalensis," Phytochemistry, vol. 40, no. 1, pp. 279-281, 1995.

[2] H. G. Park, S. Y. Yoon, J. Y. Choi et al., "Anticonvulsant effect of wogonin isolated from Scutellaria baicalensis," European Journal of Pharmacology, vol. 574, no. 2-3, pp. 112-119, 2007.
[3] H. Cao, Y. Jiang, J. Chen et al., "Arsenic accumulation in Scutellaria baicalensis Georgi and its effects on plant growth and pharmaceutical components," Journal of Hazardous Materials, vol. 171, no. 1-3, pp. 508-513, 2009.

[4] C. Zhang, Y. Zhang, J. Chen, and X. Liang, "Purification and characterization of baicalin- $\beta$-D-glucuronidase hydrolyzing baicalin to baicalein from fresh roots of Scutellaria viscidula Bge," Process Biochemistry, vol. 40, no. 5, pp. 1911-1915, 2005.

[5] M. Himeji, T. Ohtsuki, H. Fukazawa et al., "Difference of growth-inhibitory effect of Scutellaria baicalensis-producing flavonoid wogonin among human cancer cells and normal diploid cell," Cancer Letters, vol. 245, no. 1-2, pp. 269-274, 2007.

[6] Z. Gao, K. Huang, X. Yang, and H. Xu, "Free radical scavenging and antioxidant activities of flavonoids extracted from the radix of Scutellaria baicalensis Georgi," Biochimica et Biophysica Acta-General Subjects, vol. 1472, no. 3, pp. 643-650, 1999.

[7] C. Li, L. Zhang, G. Lin, and Z. Zuo, "Identification and quantification of baicalein, wogonin, oroxylin $\mathrm{A}$ and their major glucuronide conjugated metabolites in rat plasma after oral administration of Radix scutellariae product," Journal of Pharmaceutical and Biomedical Analysis, vol. 54, no. 4, pp. 750$758,2011$.

[8] H.-B. Li and F. Chen, "Isolation and purification of baicalein, wogonin and oroxylin A from the medicinal plant Scutellaria baicalensis by high-speed counter-current chromatography," Journal of Chromatography A, vol. 1074, no. 1-2, pp. 107-110, 2005.

[9] M.-C. Lin, M.-J. Tsai, and K.-C. Wen, "Supercritical fluid extraction of flavonoids from Scutellariae Radix," Journal of Chromatography A, vol. 830, no. 2, pp. 387-395, 1999.

[10] Y. Jin, Y. S. Kim, Y. D. Cheng, and K. J. Lee, "Extraction of kurarinone and leachianone A from Sophora flavescens ait using ultrasonic wave," Asian Journal of Chemistry, vol. 24, no. 7, pp. 2917-2920, 2012.

[11] H. Wang, L. Chen, Y. Xu et al., "Dynamic microwave-assisted extraction coupled on-line with clean-up for determination of caffeine in tea," LWT-Food Science and Technology, vol. 44, no. 6, pp. 1490-1495, 2011.

[12] K. J. Lee, S. D. Choi, and J. Y. Ma, "Phytochemical analysis of curcumin from turmeric by RP-HPLC," Asian Journal of Chemistry, vol. 25, no. 2, pp. 995-998, 2013.

[13] Y.-J. Li, J. Chen, and P. Li, "Identification and quantification of free radical scavengers in the flower buds of Lonicera species by online HPLC-DPPH assay coupled with electrospray ionization quadrupole time-of-flight tandem mass spectrometry," Biomedical Chromatography, vol. 26, no. 4, pp. 449-457, 2012.

[14] H. A. G. Niederländer, T. A. van Beek, A. Bartasiute, and I. I. Koleva, "Antioxidant activity assays on-line with liquid chromatography," Journal of Chromatography A, vol. 1210, no. 2, pp. 121-134, 2008.

[15] N. Pellegrini, M. Ying, and C. Rice-Evans, "Screening of dietary carotenoids and carotenoid-rich fruits extract for antioxidant activities applying 2, 2' -azobis (3-ethylbenzothine-6-surfonic acid) radical cation decolorization assay," Methods in Enzymology, vol. 299, pp. 384-389, 1999.

[16] A. J. Stewart, W. Mullen, and A. Crozier, "On-line highperformance liquid chromatography analysis of the antioxidant activity of phenolic compounds in green and black tea," Molecular Nutrition and Food Research, vol. 49, no. 1, pp. 52-60, 2005.

[17] H.-J. Choi, O.-H. Kang, P.-S. Park et al., "Mume Fructus water extract inhibits pro-inflammatory mediators in 
lipopolysaccharide-stimulated macrophages," Journal of Medicinal Food, vol. 10, no. 3, pp. 460-466, 2007.

[18] Y.-C. Oh, W.-K. Cho, Y. H. Jeong et al., "Anti-inflammatory effect of Sosihotang via inhibition of nuclear factor- $\kappa \mathrm{B}$ and mitogen-activated protein kinases signaling pathways in lipopolysaccharide-stimulated RAW 264.7 macrophage cells," Food and Chemical Toxicology, vol. 53, pp. 343-351, 2013.

[19] J.-H. Park, R.-Y. Kim, and E. Park, "Antioxidant and $\alpha$ glucosidase inhibitory activities of different solvent extracts of skullcap (Scutellaria baicalensis)," Food Science and Biotechnology, vol. 20, no. 4, pp. 1107-1112, 2011.

[20] L.-L. Dong, Y.-J. Fu, Y.-G. Zu et al., "An enhanced preparation and purification of the major antioxidants baicalein and wogonin from Scutellariae radix," Food Chemistry, vol. 133, no. 2, pp. 430-436, 2012.

[21] C. Li, L. Zhou, G. Lin, and Z. Zuo, "Contents of major bioactive flavones in proprietary traditional Chinese medicine products and reference herb of Radix Scutellariae," Journal of Pharmaceutical and Biomedical Analysis, vol. 50, no. 3, pp. 298306, 2009.

[22] H.-B. Li, Y. Jiang, and F. Chen, "Separation methods used for Scutellaria baicalensis active components," Journal of Chromatography B: Analytical Technologies in the Biomedical and Life Sciences, vol. 812, no. 1-2, pp. 277-290, 2004. 

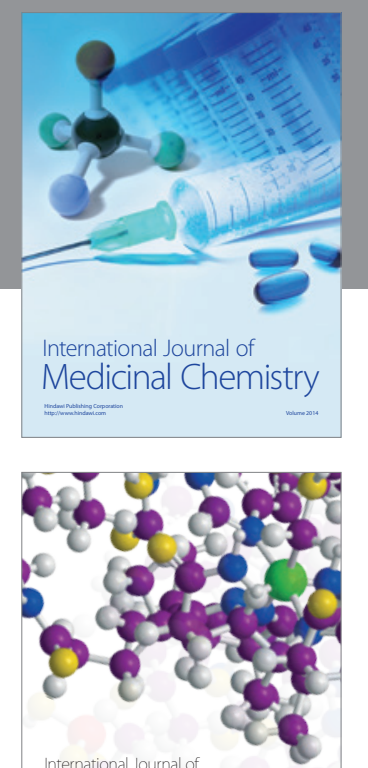

\section{Carbohydrate} Chemistry

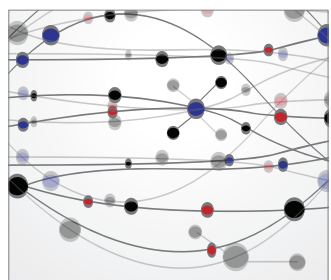

The Scientific World Journal
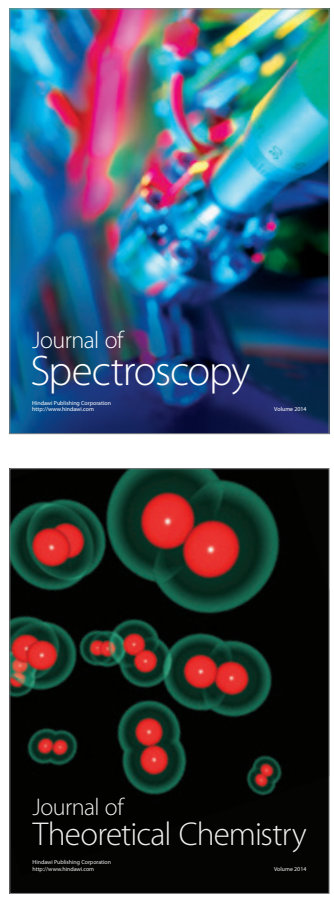
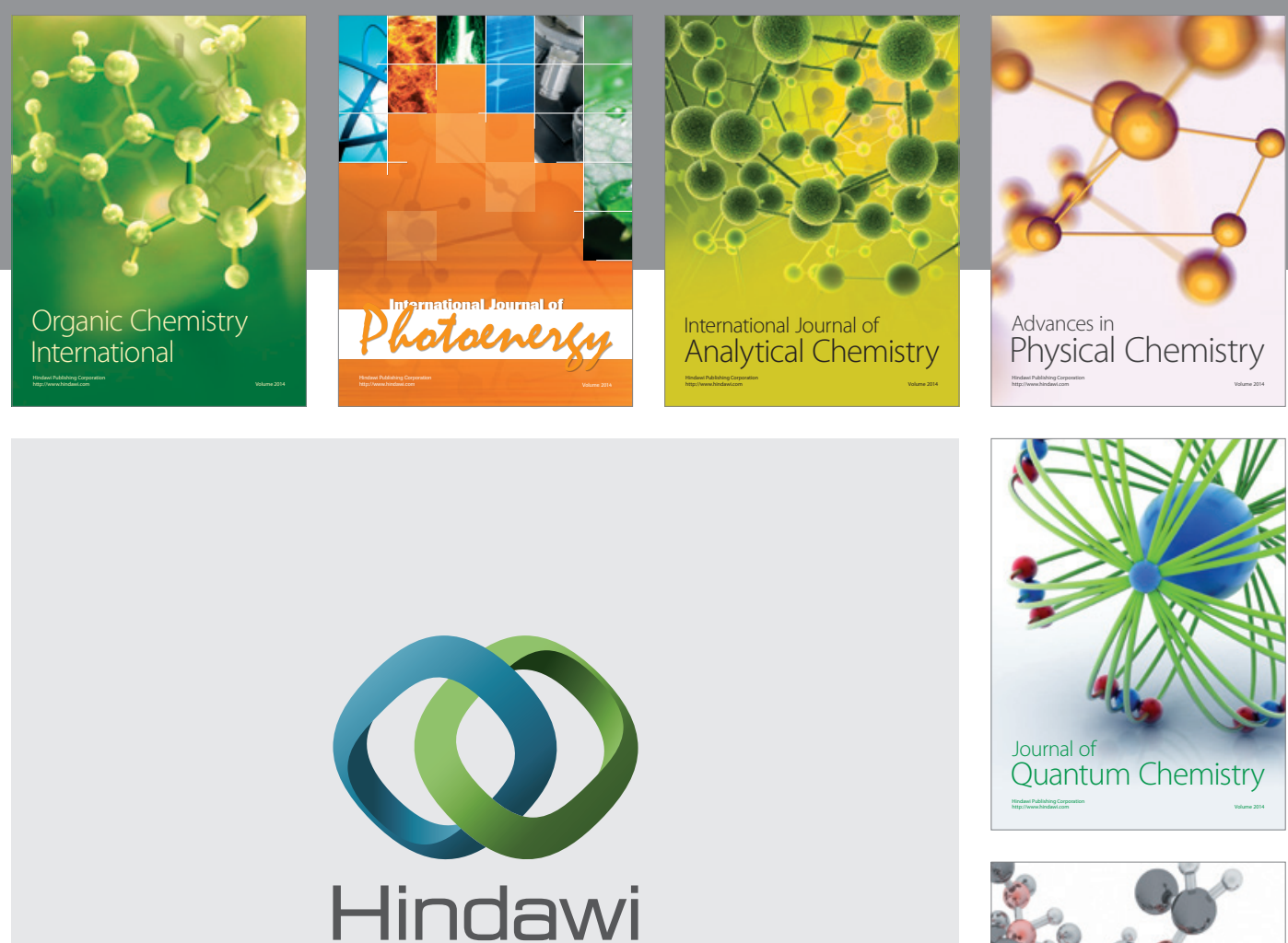

Submit your manuscripts at

http://www.hindawi.com

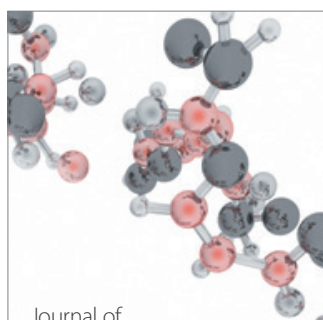

Analytical Methods

in Chemistry

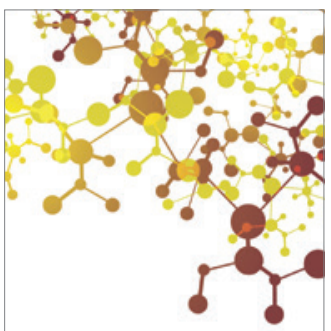

Journal of

Applied Chemistry

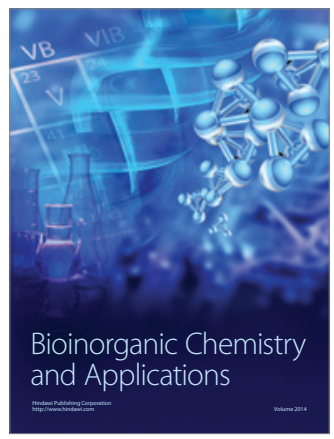

Inorganic Chemistry
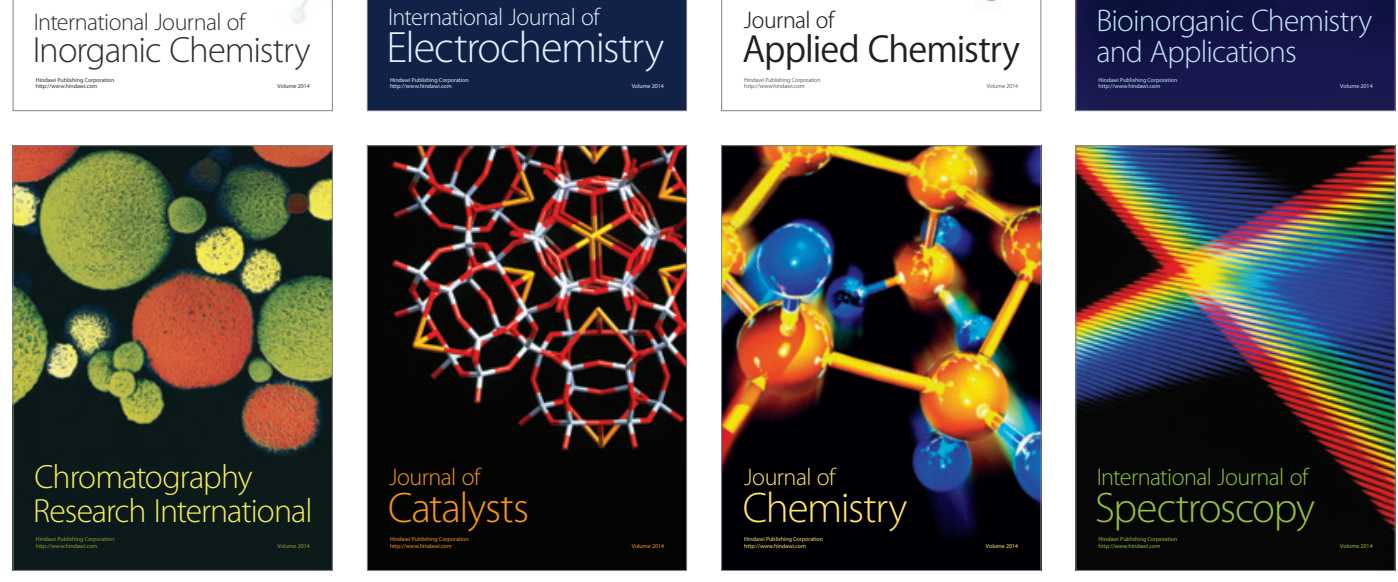